UDC: $305-055.2: 343.611$

DOI: https://doi.org/10.18485/beoiber.2018.2.1.15

\author{
William Roberto Daros ${ }^{1}$ \\ Universidad Adventista del Plata \\ Argentina
}

\title{
FEMINICIDIO: VIOLENCIA DE GÉNERO DESDE ARGENTINA
}

\begin{abstract}
Resumen
El presente artículo presenta primeramente una aclaración de los términos más utilizados sobre la temática del feminicidio y una breve referencia histórica al trato que culturalmente se le ha dado a la mujer. Se considera, luego, a la violencia contra la mujer como una manifestación de las relaciones de poder históricamente desiguales entre mujeres y hombres. Se considera que la violencia contra la mujer está constituida como un círculo formado por la violencia directa (física), la violencia estructural (en las estructuras sociales sobre todo mediante las leyes y las costumbres) y la violencia cultural. Se hace referencia al hecho actual de los feminicidios y a las formas en que se presenta. Se pasa a mencionar las explicaciones psicológicas y sociológicas de la violencia de género y la ausencia de decisiones políticas comprometidas. Se concluye con la necesidad de reorganizar la mentalidad social para lograr a largo plazo una convivencia social humana, erradicando la impunidad en los casos presentados, haciendo valer los derechos humanos $y$ reconociendo el cambio de paradigma, en los ámbitos político, social y cultural, donde la mujer se construye como un sujeto, capaz de crear, innovar y poner los estándares que se necesiten para el pleno desarrollo de su vida.
\end{abstract}

Palabras clave: feminicidio, violencia, relaciones de poder, mentalidad social.

\section{FEMICIDE: GENDER VIOLENCE FROM ARGENTINA}

\begin{abstract}
This article first presents a clarification of the most frequently used terms on the subject of femicide and a brief historical reference to the treatment that has been culturally given to women. Violence against women is then seen as a manifestation of historically unequal power relations between women and men. Violence against women is considered to be a circle formed by direct (physical) violence, structural violence (in social structures, primarily through laws and customs) and cultural violence. This text makes reference to the current fact of femicides and the ways in which they are presented. We go on to mention the psychological and sociological explanations of gender violence and the absence of committed political decisions. It concludes with the need to reorganize the social mentality in order to achieve long-term

1 daroswr@yahoo.es
\end{abstract}


human social coexistence, eradicating impunity in the cases presented, asserting human rights and recognizing the paradigm shift, in the political, social and cultural spheres, where the woman is constructed as a subject, capable of creating, innovating and setting the standards that are needed for the full development of her life.

Key words: femicide, violence, power relationships, social mentality.

El miedo de la mujer a la violencia del hombre es el espejo del miedo del hombre a la mujer sin miedo.

La exhibición de la mujer es sentida equivocadamente por el hombre como una provocación.

\section{Introducción: el género y el feminicidio}

1. Una de las tareas de los que se dedican a la filosofía se halla en pensar eso que nos pasa, sea en forma de hecho individual como social.

Algunos historiadores, sociólogos y grupos feministas han resaltado la quema de brujas, la cacería de brujas o la brujo-manía. Históricamente las mujeres han desafiado diferentes situaciones, donde se limitan sus condiciones y derechos de manera particular, de acuerdo a cada época y contexto cultural y social, con castigos que se reflejan como ejemplo para algunas y advertencia para todas (cfr. García Soormally 2011; Giberti 2010).

De hecho, en el siglo XXI ha tomado relevancia el feminicidio. Los hechos se constatan: están o no, acaecen o bien no; pero la explicación de los hechos implica encontrarles una causa proporcionada, aunque esto no signifique justificar moralmente estos hechos.

Los feminicidios implican la muerte $y$, así, constituyen la forma más extrema e irreversible de esta violencia y de ataque a los derechos humanos. Es necesario comprender los derechos como conquistas ganadas por quienes desean poseerlos y no como regalos endebles a quien los reclama.

Sin demonizar a todos los hombres ni beatificar a todas las mujeres, la necedad, el odio, la crueldad y la saña de algunas personas hacen pensar filosóficamente estos hechos y nos recuerdan la expresión de Thomas Hobbes (Homo homini lupus). De hecho, en 1997, el caso de Ana Orantes, sucedido en España (cfr. Vergés Bosch 2012: 148), que fue quemada viva en el patio de su casa por su ex marido unos días después de explicar en televisión su calvario de malos tratos; además, el juez la había condenado a seguir viviendo en la misma casa que el agresor después de denunciarlo, hace pensar también en la construcción de nuevas formas jurídicas y de aplicación de las mismas.

2. La palabra feminicidio, así como la variante femicidio, son formas válidas para aludir al asesinato de una mujer por razón de su sexo, como una forma de violencia machista. 
La primera persona que utilizó el término "femicide", en inglés, directamente vinculado a la violencia de género fue Diana Russell en 1976 ante el Primer Tribunal Internacional de Crímenes contra Mujeres. Desde entonces, su contenido y alcance ha variado. La propia Diana Russell lo definió, inicialmente, junto con Jane Caputi, como el "asesinato de mujeres realizado por hombres motivado por odio, desprecio, placer o un sentido de propiedad de la mujer" ${ }^{2}$.

El trato que las mujeres han recibido de parte de los hombres ha sido muy variado, según los tiempos y las culturas en que nos ubicamos.

En las sociedades occidentales, de forma particular, y en las investigaciones en torno a la construcción de identidades, el género alude a un sistema particular de clasificación sociocultural que divide a los integrantes de la población humana en sujetos masculinos o femeninos, según consideraciones teóricas en torno a la potencia explicativa del género y las características sexuales del cuerpo; esta clasificación permite a las sociedades socializar a sus miembros de tal manera que se reproduzca el modelo que establece las prácticas, los roles, las normas, los comportamientos y las relaciones propias de cada sexo (macho o hembra), construyendo así sujetos masculinos o femeninos específicos. Tenemos entonces que género alude a un sistema simbólico que establece las diferencias de comportamiento y actuación de hombres o mujeres, asumiendo un modelo de clasificación binario excluyente.

El término género tiene diversas acepciones. Son varias y de diferente índole las dificultades para utilizar esta categoría. La primera es que el término anglosajón gender no se corresponde totalmente con el español género: en inglés tiene una acepción que apunta directamente a los sexos. Gender remite gramaticalmente, en la lengua inglesa, a masculino o femenino o bien a la capacidad de engendrar; mientras que en español se remite a la clase, especie o tipo a la que pertenecen las cosas dentro de un grupo taxonómico, a los artículos o mercancías que son objeto de comercio y a la tela, para indicar qué calidad o textura tienen los objetos. Al comprar un paño para confeccionar una prenda de vestir se puede preguntar "iDe qué género es?" que no tiene referencia alguna a los sexos.

Decir en inglés "vamos a estudiar el género" lleva implícito que se trata de una cuestión relativa a los sexos; plantear lo mismo en español resulta críptico para los no iniciados: ise trata de estudiar qué género: un estilo literario, un género musical o una tela? En español la connotación de género como cuestión relativa a la construcción de lo masculino y lo femenino sólo se comprende en función del género gramatical, pero únicamente las personas que ya están en antecedentes del debate teórico al respecto lo comprenden como relación entre los sexos, o como simbolización o construcción cultural (cfr. Collignon Goribar, Lazo Corvera 2017: 54; Lamas 1995: 9-53).

2 Aunque femicide, argumenta Diana Russell, ha estado en uso desde hace más de dos siglos y apareció por primera vez, en la literatura, en A Satirical View of London (Inglaterra, 1801) para denominar "el asesinato de una mujer" (Russel 2005). 
Si nos volvemos ahora, a la antigüedad cultural lejana, las mujeres eran diosas, las únicas capaces de dar vida, de crear vida. Los hallazgos de una serie de amuletos y figuras al norte de Israel y el sur de Siria, permiten entender que existió incluso una devoción real por "Asherah", unida a la adoración a Yahveh. Al parecer, eran una pareja. Probablemente, Yahveh hacía las veces de "Dios Padre" o "esposo" de Asherah. Y ella, por su parte, era la "Diosa madre", la que dio origen a todos los hombres.

La Biblia, podríamos decir, que así lo confirma. Fue tal la admiración que sintió luego el pueblo de Israel por esta deidad, que habrían levantado una estatua en su honor en el mismísimo Templo de Salomón (2 Reyes 21:7; 23:6,7).

Los profetas Isaías, Jeremías y Miqueas de hecho condenaron la idolatría de Asherah, ya que según ellos alejaba de la adoración del dios único y verdadero. Esto nos da idea de cómo la diosa femenina, del árbol de la vida, del mar y del cielo, fue equiparada con la falsa idolatría, con Baal, y se alejó al hombre de la adoración de la pareja divina y de la mujer, probablemente en ediciones subsecuentes de la Biblia, editada por hombres que quizás más que ser fieles a la sagrada escritura y a los documentos históricos, hicieron una operación de inteligencia y una programación filomasculina de la sociedad, destinada a mantener en el poder a la casta sacerdotal netamente masculina, reprimiendo el polo femenino de la divinidad. Algo semejante se advierte en el proceso de masculinización del poder en el Nuevo Testamento, donde las diaconizas o servidoras desaparecen de la escena en los primeros siglos del cristianismo. ${ }^{3}$

3. Cuando de la vida nómade se pasó a la sedentaria y se adquirieron propiedades, los machos, ( $y$ el macho mayor: padre de padres, origen del patriarcado) por su fuerza y a la fuerza, se enriquecieron con las posesiones de personas y cosas. Las mujeres eran bienes que hacían crecer la propiedad humana de hijos. La mujer es una cosa más entre otras que no se debe codiciar ni robar: "No codiciarás la casa de tu prójimo, no codiciarás la mujer de tu prójimo, ni su siervo, ni su criada, ni su buey, ni su asno, ni cosa alguna de tu prójimo" (Deut. 5,21).

Desde la interpretación del Génesis, según el cual Dios crea a la mujer de las costillas de Adán, la mujer fue considerada como inferior al hombre hasta el siglo XX. Pablo de Tarso tan inclinado a no apegarse a la Ley mosaica en temas no fundamentales, en este punto apela, sin embargo, a la ley. En algunos de sus escritos se acentúa esta forma de considerar a la mujer:

Hagan como se hace en todas las Iglesias de los santos: que las mujeres estén calladas en las asambleas. No les corresponde tomar la palabra. Que estén sometidas como lo dice la Ley, y si desean saber más, que se lo pregunten en casa a su marido. Es feo que la mujer hable en la asamblea (I Corintios, 14: 34-35).

${ }^{3}$ Pablo menciona, en Romanos 16, una larga lista de agradecimientos en la que aparecen mujeres como Febe, recomendada diaconisa de la iglesia de Cencrea que ha ayudado a muchos; también a María, Trifena, Trifosa, Pérsida, Julia y la hermana de Nereo. Todas ellas fieles seguidoras que no solo realizaban un apostolado a nivel local sino también misionero fuera de sus propias iglesias (cfr. Gil Soldevilla 2009). 
Dejemos de lado ahora al libertino "San" Agustín que abandonó a su mujer y a su madre y finalmente se hizo monje, pero que reforzó en toda la Edad Media la idea del pecado original, donde Eva es la causante de la expulsión del Edén que fue el lugar de la presencia de todos los bienes con ausencia de dolor. La Edad Media prosigue esta apreciación (cfr. Opitz 1992: 321-390; Thomasset 1992: 61-92). En la relación estrecha entre ambos sexos, no se deja de describir a la mujer por referencia al hombre; los órganos femeninos acaban siendo siempre objeto de juicios despreciativos, sosteniendo que constituyen copias muy inferiores e imperfectas de los órganos masculinos. La mujer se considerará así un varón fallido (cfr. Rosales 2013: 32-42).

4. El siglo XIX produce un buen ejemplo del debate entre naturaleza y cultura sobre el tema de la diferencia ( $y$ desigualdad) de las mujeres (cfr. Reverter-Bañón 2016: 959-979). Precisamente de la mano de John Stuart Mill y Charles Darwin se puede entender en parte el sentido del debate. Mill recalcó que lo que se llamaba "naturaleza de la mujer" es algo "eminentemente artificial", resultado de fuerzas de represión en muchas direcciones que acaban diciendo que lo que es natural es meramente "lo que es habitual". Mas Ch. Darwin, en su libro The Descent of Man, and Selection in Relation to Sex (1871), acomodó las teorías de inferioridad de las mujeres a su teoría evolutiva, afirmando, un tanto ambiguamente, que "the man has ultimately become superior to Woman".

Las teorías decimonónicas mantenidas por fisiólogos, anatomistas y biólogos consideraban la inferioridad intelectual de las mujeres como un hecho que tenía su explicación en la inferioridad de peso del cerebro femenino; exactamente cinco onzas menos (130 g).

En el siglo XXI, parece requerirse una revisión de las conclusiones a las que la comunidad científica pueda haber llegado en el tema de las diferencias sexuales en el cerebro con las aportaciones neurocientíficas respecto a la posibilidad de seguir hablando de diferencias en el cerebro entre mujeres y hombres.

Mas una golondrina no hace verano. No pocos estiman que son pseudocientíficas aquellas creencias que de forma prejuiciosa y acientífica son mantenidas por parte de la misma comunidad científica. Un alto grado de acuerdo entre los principales autores que han ofrecido propuestas de criterios acerca de la carencia de cientificidad son los siguientes: a) creencia en la autoridad como criterio para creer y aceptar lo que se afirma como verdadero o falso; b) imposibilidad de repetición de experimentos es un indicador de carencia de cientificidad; c) ejemplos elegidos de forma que no son representativos de la categoría general a la que refieren; d) la poca o nula voluntad de comprobación o de refutación de la teoría constituye otro indicador de la carencia de cientificidad; la negación o desestimación de otras teorías o experimentos que entren en conflicto con la teoría; e) la construcción de subterfugios para que la prueba de una teoría sólo pueda ser confirmada, no refutada, por el resultado; $y, f)$ el abandono de las explicaciones sin 
sugerir posibles reemplazos y sin posibilidad de progresión teórica en el conocimiento aportado por las conclusiones de la teoría.

5. En la actualidad, el término neurosexismo refiere a las posturas sexistas, acríticas y acientíficas que, basadas en una ideología patriarcal imperante, pretenden demostrar que el cerebro de mujeres y hombres es diferente simplemente por ser mujeres y hombres (cfr. Fine 2010). Frente al neurosexismo aparece otro neologismo, neurofeminismo, que refiere precisamente a la respuesta crítica al anterior. El neurofeminismo pretende hacer una revisión crítica de las teorías científicas para desvelar cuánto de ideológico y cuánto de verdaderamente científico hay en las teorías sobre la diferencia sexual del cerebro.

Lo que nos descubre una mirada crítica es que la desigualdad no es innata, ni biológica, sino que está construida social y culturalmente sobre la diferencia sexual. La designación de género, tan antigua como el lenguaje y su codificación en las gramáticas (masculino, femenino y neutro), pasó en la actualidad a designar el género femenino (problemas de género, víctimas de género, etc.), aunque también existe, menos frecuentemente por cierto, el "masculinicidio" (u homicidio), o abuso por parte de las mujeres y más o menos sutiles formas de violencia sobre hombres: una palabra a tiempo puede matar o humillar sin que uno se manche las manos (cfr. Hirigoyen 5).

Por medio de palabras aparentemente anodinas, de alusiones, de insinuaciones o de cosas que no se dicen, es posible desestabilizar a alguien, o incluso destruirlo, sin que su círculo de allegados llegue a intervenir. El o los agresores pueden así engrandecerse a costa de rebajar a los demás, y evitar cualquier conflicto interior o cualquier estado de ánimo al descargar sobre el otro la responsabilidad de lo que no funciona: “iNo soy yo, sino el otro, el responsable del problema!». Si no hay culpa, no hay sufrimiento. Aquí se trata de perversidad en el sentido de perversión moral.

6. La teoría feminista ha demostrado de manera contundente cómo, sobre los géneros, se construye una diferencia sexual biológica, una diferencia social, cultural y personal que conduce a una notable desigualdad entre los sexos; pero ciertos grupos sólo admiten una diferencia basada en lo biológico. Más existe biológicamente la reproducción asexual. ${ }^{4}$ No siempre existió la diferencia de género (¿ni siempre existirá, pues el gen masculino es recesivo ${ }^{5}$ ); pero en el estado actual, ambos géneros poseen

${ }^{4}$ Se caracteriza por la ausencia de fusión de células: existe una multiplicación de los individuos por otros mecanismos; puede ser a partir de células vegetativas (multiplicación vegetativa) por fragmentación o a partir de células o cuerpos especiales (Universidad Nacional del Nordeste, Facultad de Ciencias agrarias, Corrientes s.a.).

${ }^{5}$ Según la científica australiana Jenny Graves, el cromosoma responsable de los genes masculinos está en proceso de extinción, aunque podría tardar millones de años antes de que suceda. Según su teoría, la diferencia de la estabilidad de los cromosomas de las mujeres radica en que dos de ellos con mil genes cada uno aproximadamente, mientras que el hombre sólo tendría una centena en el cromosoma masculino. En el caso de que un gen sea dañado, éste se puede reemplazar, en el caso de las mujeres, a partir del cromosoma restante. Sin embargo, esto es imposible para los hombres y por eso el cromosoma masculino podría desaparecer en unos cinco millones de años. No obstante, los científicos aseguran que para entonces la ciencia podría haber producido una cura revolucionaria (cfr. "Gen masculino podría extinguirse..." 2013). 
impulsos ciegos y fuertes con los que prolongan la vida de la especie. En la clase de los mamíferos, se advierte cierta violencia del macho sobre la hembra; mas este hecho no justifica el feminicidio, pues los mamíferos no matan a sus hembras aunque frecuentemente las persigan sexualmente en los períodos de celo. Las hembras se hacen renuentes o atractivas ante los machos y éstos despliegan sus atributos ante las hembras, como lo hace manifiestamente el pavo real.

Otros grupos fundamentan el feminicidio en lo cultural y social. Como ya dijimos, en el inicio de nuestras culturas la mujer era una diosa para el hombre, pues era la única creadora de vida, que podía hacer nacer un hijo. Mas, cuando se formaron grupos humanos, se adquirieron propiedades y el hombre por su fuerza debió defenderlas, las hembras y sus críos pasaron a ser parte de sus bienes y objeto de rivalidad y defensa.

Más difícilmente se fue admitiendo una diferencia por la forma en que cada persona vive su género. "Género", en efecto, menciona biológicamente lo que es común a varias especies y no se admite entonces una diferencia personal. Judith Butler (2002: 32) socialmente:

Define "género" como "un modo de organización de las normas culturales pasadas y futuras y un modo de situarse uno mismo con respecto de esas normas"; es decir, fundamentalmente, como "un estilo activo de vivir el propio cuerpo en el mundo, como un acto de creación radical”.

Parece que se requiere que lo biológico, lo social y lo personal sean considerados en interacción mutua. Lo biológico considerado aisladamente nos deja en el campo de lo animal; lo social considerado aisladamente nos mantiene en el ámbito de lo impersonal; y lo personal tomado como único factor determinante de lo que somos nos aísla del mundo y nos hace utópicos y asociales. Por otra parte, acentuar uno u otro género lleva al machismo y al feminismo, dos extremos parciales y perniciosos. Mas parece, finalmente, manifiesto que es el sexo lo que empieza y termina asignando el género.

Por "género" puede entenderse "la forma de los modos posibles de asignación a seres humanos, en relaciones duales, familiares o sociales, de propiedades y funciones imaginariamente ligadas al sexo". (Santa Cruz et al. 1994).

Es imperioso, pues, todo un movimiento de ciencia y filosofía críticas, en diálogo con otras disciplinas, que garanticen la autonomía académica y promuevan

Cromosoma $\mathrm{Y}$ tiene menos de 200 genes, contra 1.100 del cromosoma $\mathrm{X}$. El cromosoma $\mathrm{Y}$, responsable de asignar el sexo masculino, perdió rápidamente sus genes, y esto ipodría llevar a su desaparición progresiva?, se preguntan dos genetistas de la Universidad Estatal de Pensilvania, Estados Unidos. Los científicos aclaran que esto no significa el final del sexo masculino. Según el estudio, los genes que desaparecieron no eran determinantes para la supervivencia de la especie (Rodríguez 2009). 
comportamientos responsables con las normas y valores asumidos por las sociedades, las instituciones, y las personas (cfr. Segato 2003).

\section{Violencia, machismo y patriarcado}

7. La violencia en cualquiera de sus manifestaciones es una conducta intencional, que puede tener componentes de aprendizaje familiar y/o cultural cuyo objetivo es controlar mediante el ejercicio del poder (cfr. Córdoba, Pérez 2011: 5-42).

La violencia contra la mujer es una manifestación de las relaciones de poder históricamente desiguales entre mujeres y hombres, que han conducido a la dominación de la mujer por el hombre, la discriminación contra la mujer y a la interposición de obstáculos contra su pleno desarrollo. La violencia contra la mujer a lo largo de su ciclo vital dimana esencialmente de pautas culturales, en particular de los efectos perjudiciales de algunas prácticas tradicionales o consuetudinarias y de todos los actos de extremismo relacionados con la raza, el sexo, el idioma o la religión que perpetúan la condición inferior que se asigna a la mujer en la familia, el lugar de trabajo, la comunidad y la sociedad (Informe de la cuarta... 1996: 52).

La violencia contra la mujer está constituida como un círculo formado por la violencia directa (física), la violencia estructural (en las estructuras sociales sobre todo mediante leyes y las costumbres) y la violencia cultural. Ésta es la formada por aspectos de la cultura y de la esfera simbólica (religión, ideología, arte, lenguaje, ciencias, clasificaciones naturalizadas, esquemas de percepción, de apreciación y de acción que constituyen los hábitos), porque este tipo de violencia es la que se utiliza para justificar o legitimar la violencia directa y la estructural. La fuerza simbólica, por lo tanto, "es una forma de poder que se ejerce directamente sobre los cuerpos y como por arte de magia, al margen de cualquier coacción física", es una violencia que se ejerce de manera suave, invisible e insidiosa en lo más profundo de los cuerpos (Bourdieu 2000: 54).

Esta violencia está sostenida, en parte, por una visión cultural que supone que: a) las mujeres son menos que los hombres $\mathrm{o}$ b) son posesiones de los hombres, c) las mujeres están para servir a los hombres, y d) hay cosas que los hombres pueden hacer $y$ las mujeres no, y viceversa.

Cuando una mujer está más vulnerable o en riesgo de ser violentada por los agresores es cuando ellos tienen esa sensación de pérdida inminente, cuando se va a romper un vínculo, o ya se ha roto. Al convencerse de la no recuperación aumenta la peligrosidad de la violencia masculina: “Esta mujer es y será mía y de nadie más, o la mato". Estos hombres no manifiestan una grandeza de ánimo capaz por la que podrían vivir y dejar vivir a cada uno con autonomía; sino una mezquindad ciega, torpe, violenta, inhumana.

La mayoría los feminicidios se dan en estas situaciones. De hecho los varones no asumen su conducta como violenta. No hay reconocimiento de violencia, sino más bien 
justificación de su conducta o la de otros varones, que han naturalizado la violencia. Lo que es cultural se ha hecho natural y, por lo tanto, sin culpa para los agresores. Se da una educación no formal (no escolarizada), familiar y social, que sienta las bases de la desvalorización y la violencia; cuando se vincula a la mujer al desvalimiento y a la sumisión, y se omite enseñarle sus derechos y la concientización de su dignidad como persona, y cuando se modela al hombre en la brutalidad como sinónimo de virilidad. La educación no formal moldea no sólo las formas de pensar sino que establece también la manera de expresar los sentimientos para los hombres y las mujeres. Esto se refuerza continuamente de manera que se llega a tomar como normal la actitud que encierra contenidos discriminatorios para ambos; como por ejemplo, el considerar que la mujer debe ser más emotiva, y asociar a los hombres a la rudeza y la agresividad.

La sociedad legitima la violencia en el caso de la pareja, avalada por la perduración de una cultura patriarcal, que adjudica al hombre y a la mujer roles donde la subordinación de la mujer al marido es lo establecido como correcto, ya que la jerarquía de poder está basada en la diferenciación sexual. Argentina pertenece a las naciones nacidas bajo el poder de España y de la Iglesia Católica, que le legaron una visión masculina y jerarquizada del poder.

En este contexto, aunque sean dos conceptos muy relacionados, el machismo y el patriarcado no hacen referencia a lo mismo. El machismo es un conjunto de creencias, sesgos cognitivos y actitudes que predisponen a las personas a actuar como si la mujer tuviese menos valor que el hombre, mientras que el patriarcado es definido como un fenómeno social donde el padre es jefe de un clan (o grupo de familias) el que históricamente ha sido el motor del machismo y de ciertos privilegios de los que solo disfruta el hombre.

Mientras que el machismo es expresado a través de los individuos, el patriarcado es algo que existe en los grandes colectivos, una dinámica de poder que solo se entiende si tenemos en cuenta a muchas personas a la vez.

8. El machismo no es solo un sistema de dominación cultural. Cuando se habla de machismo, muchas veces tendemos a pensar que este es solo un fenómeno psicológico, una manera de pensar en la que la mujer queda minusvalorada y cosificada. Sin embargo, desde los estudios de género y el feminismo se acostumbra a hablar del machismo generado por el patriarcado como un fenómeno que tiene dos pilares: uno psicológico, basado en cómo piensan y actúan los individuos, y otro material, basado en características objetivas de nuestro entorno e instituciones: ropa, películas, leyes, etc.

De este modo, el aspecto psicológico y el material se retroalimentarían, dando lugar a individuos cuyas actitudes machistas son reforzadas por el medio en el que viven y que ellos contribuyen a reproducir mediante sus acciones.

El machismo, como construcción cultural, es un modo particular de concebir el rol masculino, modo que surge de la rigidez de la mayor parte de las sociedades del 
mundo contemporáneo, para establecer y agudizar las diferencias de género entre sus miembros. Es así como se generan expectativas de comportamiento en torno del varón que incluyen valores y actitudes, conformando de este modo una concepción ideológica asentada en la superioridad del macho en relación con la hembra, superioridad que se ha pretendido fundamentar desde distintas perspectivas ideológicas a lo largo de la historia del pensamiento (Rodríguez Kauth et al. 1993: 275).

9. Como el patriarcado está conceptualizado como un sistema universal, extendido por todo el mundo que ha resistido todo tipo de cambios políticos, algunos investigadores han propuesto la idea de que su origen tiene que ver con propensiones genéticas. Concretamente, una posible explicación de su existencia sería la presunta diferenciación en el modo de comportarse de ambos sexos cuyo responsable directo sea el ADN. Según esta idea, los hombres tendrían una especie de tendencia natural al comportamiento dominador y agresivo, mientras que la mujer manifestaría con mayor facilidad conductas de sumisión.

La otra propuesta, mucho menos controvertida, es que el patriarcado se produjo a causa de dinámicas culturales en las que hombres y mujeres eran educados para que se dividiesen el trabajo, llevando esto a una situación en la que los hombres llegaron a un poder de negociación sobre las mujeres que han ido explotando a lo largo de las generaciones. Los machos al gobernar establecieron las costumbres primero, y las leyes después que reforzaron su dominio. Por ejemplo hasta el siglo XX, las mujeres aparecen como incapaces de investigación científica y de inventar; pero de hecho existía la ley europea según la cual los inventos sólo se registraban a nombre del marido de una mujer inventora. ${ }^{6}$

\section{El hecho del feminicidio}

10. El feminicidio es la manifestación más extrema del abuso y la violencia de hombres hacia mujeres. Se produce como consecuencia de cualquier tipo de violencia de género, como pueden ser las agresiones psicológicas y físicas, la violación, la maternidad forzada o la mutilación genital.

Se calcula que cada año se perpetran alrededor de sesenta seis mil feminicidios en el mundo (Figueroba). No obstante, hay que tener en cuenta que el número de casos de violencia de género tiende a infravalorarse y que muchos países no diferencian entre los homicidios y los feminicidios.

Mientras que el $80 \%$ de las víctimas de asesinato son mujeres cuando hablamos concretamente de homicidio familiar o íntimo, el porcentaje de hombres desciende a un

${ }^{6}$ La primera ley de patentes en EEUU data de 1790 , pero... solo para hombres (cfr. Caballero González 2014).

BEOIBERÍSTICA Vol. II / Número 1 (2018) | 217-247 
tercio. Este es uno de los factores que exigen por qué el feminicidio requiere ser distinguido del resto de asesinatos.

Los países con las tasas más altas de feminicidio son actualmente El Salvador, Jamaica, Guatemala, Sudáfrica y Rusia. Más de la mitad de los 25 países con mayor tasa de feminicidios están en América; además de los mencionados, en la lista se encuentran Honduras, Colombia, Bolivia, Venezuela, Brasil, la República Dominicana, Argentina.

11. La motivación para el crimen es una de las peculiaridades principales del feminicidio en relación con otros tipos de homicidio.

Según Diana Russell, algunas de las motivaciones principales para estos asesinatos son la ira, el odio, los celos y la búsqueda de placer. Otras variables que Russell considera relevantes son la misoginia, el sentido de superioridad de género y la concepción de las mujeres como posesión. Estas variables se transmiten culturalmente y favorecen la violencia de los hombres hacia las mujeres.

\section{Tipos de feminicidio}

12. Diana Russell y otros autores han propuesto diferentes tipos de feminicidio que difieren sobre todo en la relación entre la víctima y el asesino y en la motivación para el crimen.

a. Íntimo y familiar. Mientras que los feminicidios familiares son cometidos por varones dentro de su familia cercana o extendida, el concepto "feminicidio íntimo" suele usarse para hablar del asesinato de la pareja o la ex pareja, independientemente de la relación legal entre las dos personas.

El feminicidio íntimo se relaciona con el consumo de alcohol y otras sustancias y supone un 35\% de todos los asesinatos de mujeres (no sólo los cometidos por hombres), lo cual lo hace el más frecuente de todos los tipos de feminicidio.

El asesinato por honor es un tipo especial de feminicidio que se comete contra mujeres de las que se dice que han deshonrado a la familia. Entre los motivos más habituales de "deshonra" se incluyen ser víctima de violación y ser acusada de adulterio.

Asimismo en India, Irán, Pakistán y Bangladesh se perpetran asesinatos por dote. Tras el matrimonio, la familia del marido acosa y tortura a la esposa como método de extorsión para conseguir una dote mayor. En estos casos la mujer puede ser empujada al suicidio o morir asesinada, frecuentemente quemada viva cuando su familia no accede a pagar.

b. Lesbicidio. No es difícil encontrar períodos históricos en que el asesinato de mujeres - como castigo por ser homosexuales - era legal. Por ejemplo, en la Francia del siglo XIII se aprobó una ley según la cual a las mujeres se les debía amputar una extremidad las dos primeras veces que tuvieran sexo con mujeres, mientras que a la tercera debían ser quemadas. 
Un crimen similar y frecuentemente unido al lesbicidio es la violación correctiva, consistente en abusar sexualmente de una mujer homosexual con el objetivo de hacer que se comporte como si fuera heterosexual o simplemente como castigo.

Hoy en día la homosexualidad, tanto en mujeres como en hombres, sigue siendo condenada por la mayoría de religiones y es ilegal en países como Irán, Libia, India, Pakistán, Marruecos y Nigeria. Estas condiciones favorecen la violencia contra personas homosexuales, ya que la legitiman desde las instituciones.

c. Feminicidio racial. En los feminicidios raciales el componente de género se suma a un factor étnico: en estos casos el asesino mata a la víctima tanto por ser mujer como por tener rasgos culturales y físicos diferentes a los suyos.

En este tipo de asesinato el racismo no sólo influye en la comisión del crimen, sino también en que el hecho de que la víctima sea de una etnia menos valorada socialmente puede interferir en la resolución del caso, en el proceso legal y en la imagen que los medios dan de la fallecida.

d. Feminicidio en serie. Este tipo de feminicidio suele darse cuando un varón mata a mujeres de forma repetida para obtener placer sexual sádico. En general estos asesinatos se producen por trauma o por asfixia.

Las víctimas de feminicidios en serie, como el resto de feminicidios no íntimos, son más frecuentemente mujeres que trabajan como camareras o como prostitutas.

En ocasiones se atribuye el feminicidio en serie a la pornografía, en especial a aquella que erotiza la violencia. No obstante, esta relación no ha sido demostrada por el momento.

\section{Explicaciones psicológicas de la violencia de género}

13. Cuesta entender que, en el clima del amor, se llegue a matar. ¿Cómo pueden coexistir el amor y la destrucción de lo amado?

S. Freud nos da dejado una teoría psicológica de lo que racionalmente parece una contradicción y que sirve de base para la elaboración de una teoría moral. Eros, amor, representa los instintos más primitivos por satisfacer los deseos libidinosos, los de hambre y los de sed, es decir, las pulsiones de vida; mientras que Tanatos, muerte, engloba los deseos por satisfacer los impulsos de destrucción y agresividad, las pulsiones de muerte. Ambos, Eros y Tanatos, están enmarcados en el Ello, una de las instancias - de la denominada segunda tópica freudiana - de la composición de la psiquis humana, que es complementada por las instancias del Yo y el Superyó (cfr. Gago 2012; Daros 1979: 249-272). Las pulsiones que se hallan enraizadas en el Ello deben ser encauzadas por el Yo, para lograr las exigencias morales del Superyó, en el contexto de una vida social compartida. Pero el Ello es como un caballo que el Yo o jinete debe dominar usando las fuerzas del Superyó que contiene los ideales sociales y morales, para ser responsable y hacer posible la convivencia social. 
Toda relación de pareja, más o menos normal, comienza por el amor. Es posible distinguir entre el amor como pasión imaginaria y el amor como relación simbólica. En el feminicidio, el amor de quien desea ser amado realiza una tentativa de capturar al otro como objeto; es un amor narcisista y quien aspira a este amor lejos está de interesarse por el bien del amado sino que lo guía la premisa de ser amado por todo, no solo por su yo. Se trata de la acción arrasadora de la fascinación imaginaria que conduce al intento de aprisionar al otro en uno mismo, engullirlo, capturarlo como objeto en la particularidad de uno mismo (Bower, Muñoz Zaccaro 2013).

Desde un punto de vista moral se podría afirmar que quien comete feminicidio no logra generar un Ego organizado y lo suficientemente estructurado como para poder dominar las pulsiones del Ello, mediando las pautas sociales y morales del Superyó. Se podría sostener que estamos ante una persona ni educada ni moral. La educación moral es un proceso de aprendizaje que permite a los jóvenes y adultos en una comunidad comprender, practicar e interesarse por los valores éticos fundamentales tales como el respeto, la justicia, la virtud cívica, la ciudadanía, y la responsabilidad por sí mismo y por el prójimo. Sobre tales valores fundamentales, se forman las actitudes y las acciones que son propias de las comunidades seguras, saludables e informadas y sirven como los cimientos de nuestra sociedad. Esta teoría supone una concepción de un yo personal en su compleja y multiforme realidad, organizada y responsable, tanto racional como afectiva, sensitiva, expresiva y volitiva (cfr. Martínez Martín 1995).

14. Desde distintas orientaciones teóricas se podría explicar la violencia de género y el feminicidio de modos muy distintos. Veamos primeramente la cuestión desde la perspectiva del interaccionismo simbólico y desde el patriarcado.

La teoría del diverso interaccionismo simbólico implica la sociología, la psicología social y la antropología, y sostiene que las personas construimos conjuntamente símbolos que dotan de significado a la realidad en sus distintos aspectos, guiando nuestra conducta en relación con estos. En este contexto cabe advertir que tanto el hombre como la mujer interpretan, simbólica y psicológicamente, la sexualidad desde sus respectivos puntos de vista. La mujer desea manifestar sus atractivas formas, adornos y vestidos con lo cual se siente bien y hermosa; pero el hombre es excitado (erecciones) por la visión de esas formas e interpreta esta manifestación, espontánea y simbólicamente, como una provocación. Si el hombre reacciona ante tal provocación (con palabras, gestos o acciones), la mujer se sorprende y no comprende esta actitud.

Sin duda, algunas mujeres conocen esta debilidad masculina y saben aprovecharla para seducir si así lo desean y les conviene; pero otras quedan sorprendidas y malhumoradas por esta actitud masculina. Los hombres tampoco comprenden por qué las mujeres los provocan y luego se lamentan por las conductas masculinas. Se da un narcisismo espontáneo en hombres y mujeres, por el que tanto hombres como mujeres no suelen advertir la perspectiva y los sentimientos opuestos que generan en la otra parte humana. Los hombres (sobre todo si son adictos al sexo) no pueden resistir el atractivo 
femenino y llegan hasta imponer a las mujeres la obligación de cubrirse el rostro, con un velo, ante extraños o vestir hábitos que no muestren los contornos femeninos o no salir de los hogares si no están acompañadas por un varón. De allí las expresiones atribuidas a Platón (pero también presentes en las oraciones de los fariseos): Doy gracias a Dios por haber nacido griego y no bárbaro (hebreo y no gentil), doy gracias a Dios por haber nacido hombre y no mujer, doy gracias a Dios por haber nacido libre y no esclavo... ${ }^{7}$

Desde esta orientación, el feminicidio podría explicarse como una consecuencia de las diferencias en los roles otorgados a cada género por muchas sociedades: se entiende así que el ámbito público debe ser controlado por los varones y se relega a las mujeres a la reproducción y al cuidado del hogar.

En muchas ocasiones se denomina "patriarcado" a esta estructura social, que se sostiene en leyes escritas y/o en normas implícitas que refuerzan y condicionan patrones de comportamiento diferenciados en función del sexo biológico.

Según algunos sociólogos, las estructuras patriarcales se manifiestan en la mayor probabilidad que tienen las mujeres de recibir abuso, de ocuparse del hogar y de los hijos, de ser representadas con poca fidelidad en los medios y en la cultura popular, de cobrar menos que los hombres por el mismo trabajo y de que su sexualidad sea vista de forma negativa. Asimismo tienden a estar infrarrepresentadas en los ámbitos de poder y de toma de decisiones.

La concepción de las mujeres como inferiores a los hombres hace que el significado social de estos asesinatos sea menos negativo en entornos más patriarcales. De esto se podría deducir que existe una mayor probabilidad de que se dé violencia de género y por tanto feminicidio si la ley y la cultura no los penalizan.

15. Perspectivas evolucionista y biologicista. En muchas ocasiones se atribuyen las diferencias en los roles de género a la biología de hombres y mujeres. En particular se suele mencionar que los varones tienen mayores niveles de testosterona, una hormona sexual que influye en la agresividad, la dominancia y la toma de riesgos.

También se ha propuesto que el hecho de que sean las mujeres quienes se quedan embarazadas influyó históricamente en el desarrollo de las sociedades desde los

7 Platón explica en el Timeo la diferenciación entre los sexos, la creación de seres vivientes distintos al hombre. La mujer es presentada como un varón castigado. En el origen, el demiurgo crea un ser humano, pero aquellos varones que fueron cobardes y vivieron mal, en su segundo nacimiento son transmutados en mujeres. $Y$ hasta el deseo sexual es considerado un premio consuelo para el varón caído. Para Platón la mujer no posee alma racional y queda ubicada en la mera concupiscencia (puesto que su esencia es el útero), es un hombre castigado, defectuoso, en falta; y la anatomía es un destino divino e inapelable. Para Aristóteles el goce femenino en el acto sexual deviene superfluo, la mujer es sólo un recipiente del semen masculino (mujer-vaso). Sobre este destino anatómico, se funda un destino social. Aristóteles sostenía en su Política que hay entre las personas un orden jerárquico que es "natural": el macho es superior a la hembra, el amo al esclavo, el adulto al niño. Como naturalmente lo superior debe dominar lo inferior, de esa "naturaleza" se desprende una relación política: el superior gobierna y el otro es gobernado. Los esclavos por no tener facultades deliberativas, las mujeres porque en ellas predominan las emociones, los niños porque aún no poseen una razón madura, deben obedecer al único ser con racionalidad plena: el hombre libre adulto (cfr. Maffia 2014: 108-109).

BEOIBERISTICA Vol. II / Número 1 (2018) | 217-247 
comienzos de la humanidad, especialmente a partir de la adopción del sedentarismo. Desde estas perspectivas, las diferencias biológicas existentes entre géneros tienden a ser muy valoradas, en detrimento de las influencias socioculturales, como la religión.

16. Teoría distorsionada de la acción justa. Desde hace tiempo se viene defendiendo una teoría, según la cual, la muerte violenta de la mujer y el posterior suicidio del agresor se explicaría de acuerdo a la dificultad del agresor de soportar el fuerte rechazo social que su acción comporta.

Sin embargo, no parece ser esa la hipótesis correcta; el conocimiento actual nos permite comprobar como el agresor de género que termina con la vida de una mujer es escasamente permeable a los estímulos externos; así se comprueba, por ejemplo, con las experiencias obtenidas con los tratamientos desarrollados en centros penitenciarios con los agresores de género; en ellos se pone de manifiesto que el tipo más frecuente de agresor es un sujeto victimista absolutamente convencido de lo correcto de su actuación y de lo "merecido" del castigo infligido a su pareja por su desviación de las pautas y obligaciones que para con él están establecidas.

En este contexto, la ruptura (el divorcio o separación) o la amenaza creíble de la misma, parece ser el principal factor de riesgo del feminicidio. Según los estudios existentes sobre la materia, el riesgo de feminicidio de pareja se incrementa nueve veces si a la relación basada en el abuso físico y emocional se le añade una separación o amenaza de la misma por parte de la mujer (Fernández Teruelo 2011: 14).

17. Teoría de la carencia de sentido ante la ausencia de dominio. Una parte importante de los agresores violentos de género que llegan al feminicidio han conformado su modelo o esquema vital sobre la base de una relación de dominio y control absoluto de su pareja, en la que utilizan la violencia para reafirmar el dominio y, si fuera necesario, restablecer el control. La pérdida brusca de ese modelo vital (que consideraban blindado) termina con la "necesaria" eliminación física de la mujer, proceso que a veces determina la ampliación a la propia muerte del agresor (feminicidio ampliado), al entender carente de sentido su existencia sin ese modelo de dominio en torno al que gravita la misma.

El hombre maltratador, cuando tiene hijos, tiene en sus manos un ser viviente, disponible y manipulable al que puede someter a las humillaciones que él mismo padeció en otro tiempo o que sigue padeciendo. En algunos casos, cualquier alegría de su hijo le resulta insoportable. Haga lo que haga y diga lo que diga, le inflige una vejación. Tiene una especie de necesidad de hacerle pagar el sufrimiento que él mismo vivió.

Es muy fácil manipular a los niños. Éstos siempre saben excusar a quienes aman.

Su tolerancia no tiene límites. Están dispuestos a perdonárselo todo a sus padres, a asumir su culpa, a comprenderlos y a intentar saber por qué su padre o su madre están disgustados. Para manipular a un niño, se utiliza frecuentemente el recurso del chantaje emocional. 
Quien inflige violencia a otro individuo considera que éste se la merece y que no tiene derecho a quejarse. Para el agresor, la víctima no es más que un objeto que molesta. Niega su identidad y su derecho a tener sentimientos o emociones.

La víctima, ante esta agresión que no comprende, se siente sola, ya que, en todas las situaciones perversas, los que las presencian se muestran cobardes e indulgentes. Éstos temen convertirse, a su vez, en blanco de las agresiones, pero, en ocasiones, también gozan sádicamente con el espectáculo de la destrucción.

En una relación normal, siempre resulta posible poner un límite a la omnipotencia del otro u otra, e imponer un equilibrio de fuerzas, aun cuando sea necesario recurrir al conflicto. Por el contrario, un manipulador perverso no soporta la más mínima oposición a su poder y transformará cualquier relación conflictiva en odio, hasta el punto de querer destruir a su oponente (cfr. Hirigoyen 1999: 49).

Presentar una denuncia policial y jurídica es la única manera humana de terminar con el psicoterror. Pero hay que tener mucho valor, o haber llegado verdaderamente al límite para presentarla, pues implica una ruptura definitiva con la relación. Por otra parte, lamentablemente, en numerosos países, no hay ninguna garantía de que la denuncia prospere, ni de que desemboque en un resultado positivo.

\section{Explicaciones sociológicas de la violencia de género}

18. Las explicaciones establecen una relación entre los hechos y las posibles causas, lo que otorga a los hechos una justificación lógica (de causa a efectos), pero no una justificación moral.

La explicación social, en el caso que nos ocupa, supone:

a) Concepciones: se establecen como las ideas y el imaginario normal que una persona tiene sobre los roles en la pareja.

b) Expectativas de roles: se consideran las ilusiones y esperanzas que una persona tiene de que la pareja desempeñe su rol de tal o cual forma.

c) Roles en la pareja: conjunto de expectativas de comportamiento visible que se espera que exhiban cada uno de los miembros de la pareja.

Una concepción es pues lo que se piensa, una expectativa lo que se espera que ocurra y el rol se expresa en el conjunto de conductas esperadas en cada quien.

Los roles de género involucran los aspectos sociales, culturales y psicológicos asignados por construcción social a la femineidad y a la masculinidad, siendo la sociedad en general y la familia en particular los responsables del proceso de socialización que comienza en el hogar y donde se establecen las pautas y los valores respecto al rol que deben asumir tanto el niño como la niña desde pequeños.

Las tradiciones y costumbres trasmitidas en una cultura patriarcal así como el papel jugado por la religión, han servido para sostener estas concepciones de roles de género. A partir del desarrollo de la sociedad, los individuos fueron aprendiendo, las pautas 
culturales que caracterizan a cada quien según el sexo, donde lo femenino se debe subordinar a lo masculino, trasciende a todas las esferas de la vida y provoca una relación desigual de poder para el hombre y sumisión para la mujer.

La educación informal es social y envolvente: remite a todos los aspectos de la vida. Por ejemplo, entre las características del hombre golpeador, se menciona que la más predominante de aspectos psicológicos es el ser inseguro de sí mismo, esto le genera en muchos casos intensos celos de su pareja y de allí la necesidad de controlar o dominar a su esposa. Este rasgo lo disfraza y con aprendizajes sociales: con actitudes autoritarias hacia su mujer aferrándose a los valores culturales patriarcales, asociados con la masculinidad: agresividad, superioridad. Otros factores que se encuentran en los hombres golpeadores es el haber sido objeto de abusos en la niñez y o haber contemplado los abusos de su padre hacia su madre (cfr. Córdoba, Pérez 2012: 20).

19. El suceso violento entre el masculino y el femenino no es el resultado de un hecho aislado, ya que se produce de manera sistemática (cfr. Puig).

Estos sucesos suelen ser primeramente invisibles, es decir, aparecen en un entorno privado y son las mismas mujeres las que se esconden presas del pánico que les genera tener que exponer su realidad.

Muchas veces el agresor ofrece una imagen impecable hacia la sociedad, lo que por desgracia convierte la situación en un estado difícil de creer o comprender.

Existe en las víctimas la sensación de que las circunstancias que están viviendo no resultan tan graves como para manifestarlas públicamente, hecho que conlleva una dificultad añadida en el momento de buscar ayuda externa.

Todo este engranaje es fruto de una auténtica desigualdad entre hombres y mujeres derivada del código patriarcal que aún a día de hoy resuena entre la sociedad. Este código es el mismo que conduce al agresor a utilizar mecanismos de control y condena sobre la mujer (cfr. Triglia).

Las condiciones de vida de las víctimas de feminicidios están insertas en una dinámica social donde la violencia se propaga porque se encuentra asimilada de distintas maneras en la vida cotidiana; tratándose de trabajo simbólico reproducido por instituciones como la familia, la Iglesia, la escuela, el Estado y el trabajo, a partir del cual se perpetúan interacciones entre los recursos simbólicos que eternizan y naturalizan formas de violencia y discriminación de lo femenino.

Se debe considerar en el feminicidio, así como en las formas de violencia contra la mujer, el contexto histórico, social y cultural en que estos se presentan, ya que la violencia puede tener diversas finalidades, una de ellas es el amedrentar y aterrorizar, a través de la crueldad, a la mujer que ha logrado convertirse en un sujeto independiente o autónomo, y en su camino desarmar la subjetividad lograda por la misma mujer.

En este contexto, según el marxismo clásico, la sociedad de clases sería la responsable de la dominación y la discriminación de las mujeres, la explotación de la mujer no sería más que una de las expresiones de la explotación del hombre por el 
hombre, el clasismo estaría en el origen y en la raíz de cualquier forma de sexismo, la violencia de género sería una consecuencia desviada o colateral de la violencia de clase. Esta interpretación no fue verdaderamente impugnada por las primeras grandes exponentes del marxismo feminista. El primer problema que plantea esta hipótesis tradicional del marxismo es que las mujeres ya eran explotadas, oprimidas y violentadas, mucho tiempo antes de la emergencia y el desarrollo del capitalismo. De hecho, como bien sabemos, la violencia contra la mujer, así como su opresión y su explotación, pueden comprobarse todavía en comunidades pre-capitalistas que subsisten en los márgenes del capitalismo (cfr. Pavón-Cuéllar 2017: 246).

Pero tanto el Marxismo como el Psicoanálisis están concordes en afirmar que la opresión de la mujer es la primera opresión de clase, porque es la primera forma de posesión de un ser por otro. El hombre que posee a la mujer, de hecho, es el primer poseedor o propietario. Ya en la Ideología alemana, Marx y Engels (1846) habían encontrado la "primera forma de propiedad" en una familia primitiva en la que "la mujer y los hijos son los esclavos del marido" (Marx, Engels 2014: 26). Posteriormente, en los Grundrisse, Marx (1858) antepone la relación "concreta" familiar a un vínculo tan "simple" como el de la "posesión" (cfr. Marx 2009; Marx, Engels 2014).

Freud nos permitiría vislumbrar también, a través de la figura del padre primitivo en la que reposa cualquier identificación de varón, el aspecto masculino y heterosexual del poder y del privilegio, de la desigualdad y de la rivalidad, así como la condición viril inherente al propietario con su propiedad originalmente femenina.

En un sentido más amplio aún que la perspectiva psicológica y sociológica, desde un ámbito que puede llamarse cultural-ideológico (donde la verdad es impuesta desde una parte, la cual estima poseer la verdad y la justicia de su parte), el dominio del macho sobre las hembras durante siglos, para el pensamiento europeo daba por supuesto que un cuerpo negro era un cuerpo esclavo. Al enfrentarse un blanco a un negro, trataba a ese cuerpo como un cuerpo disponible. En esa cultura, el propio negro se veía a sí mismo como un "otro" inferior, por virtud de la violencia simbólica que le impedía establecer un sentido de sí mismo fuera de la producción de sentido dominante, fuera del sentido impuesto por la cultura blanca.

Desde una cultura e ideológica-patriarcal, los cuerpos de las mujeres son cuerpos apropiables. Si se resisten serán violentados, y lejos de justificarse la resistencia se justificará la violencia como forma de disciplinamiento, como manera de "poner las cosas en su lugar", aunque los lugares misóginos impuestos por el derecho, la teología y la política hayan sido establecidos sin la participación ni el consentimiento de la mujer simbólica y violentamente sometida (Maffia 2009: 209).

19. El funcionamiento de la violencia de género, según la psicóloga estadounidense Leonor Walker, discurre a través de un ciclo compuesto por tres fases.

Cuando una mujer entra en las entrañas de este círculo es cuando deja de visualizar alternativas de huida posibles y se encuentra presa de la situación. Se genera en ella una disonancia cognitiva entre el disfrute vivido en la relación y el malestar sin 
nombre que padece, porque al contrario de lo que se suele pensar no se dan sólo gritos, insultos, amenazas y golpes, hay también ternura, cariño y dulces detalles que hacen florecer en la mujer el pensamiento de haber encontrado por fin al hombre de su vida.

20. Primera fase: aumento de la tensión en la pareja. En la primera fase del ciclo, el malestar sin nombre empieza a cobrar vida, se percibe un aumento de la tensión entre ambos miembros, se establecen tímidos indicios de lo que posteriormente será la agresión, tales como gritos y pequeñas peleas. La mujer acepta estos abusos como legítimamente dirigidos a ella porque piensa que puede ser merecedora de tal agresión.

La persona agredida trata de buscar un sinfín de excusas y razones para comprender lo que está sucediendo, hasta el punto de suponer que ella misma por su conducta o actitud es quien ha provocado la ira de su agresor, y lo que más perpetúa el ciclo, tiende a pensar que con el tiempo podrá cambiar el comportamiento de su pareja, hecho que en ningún caso se cumple.

Esta fase puede llegar a tener una duración de días, semanas, meses o incluso años, antes no se desencadenan incidentes de agresión mayores. En la perspectiva del hombre, éste cada vez se encuentra más sensible, todo le molesta, se irrita con suma facilidad, y se enoja por cosas objetivamente insignificantes.

21. En la segunda fase propuesta por L. Walker se experimenta una descarga irrefrenable (furia desatada) de las tensiones que se han venido acumulando durante el transcurso de la fase anterior. Hay una falta de dominio sobre la conducta totalmente destructiva, la mujer acepta que la ira de su agresor está fuera de control, pero no puede hacer nada por calmarla, es en esta fase cuando surge la agresión física o la total destrucción psicológica.

El agresor es el único que puede poner fin a este estado. Su duración se sitúa alrededor de 2 a 24 horas, durante las cuales se culpa a la mujer de todo lo sucedido. Cabe destacar que es en este momento cuando la mujer es completamente susceptible y está abierta a recibir ayuda profesional debido al gran temor que siente por volver a ser maltratada.

22. En la tercera y última fase antes de volver a iniciar todo el ciclo, se experimenta un estado de arrepentimiento profundo por parte del agresor, el cual aprovecha la vulnerabilidad de la víctima para ofrecerle dóciles dosis de cariño y atención, mostrando en todo momento un comportamiento y una actitud de aflicción y remordimiento interno.

Es en este momento donde se perpetúa todo el ciclo de la violencia; la mujer se siente nuevamente amada y feliz, lo que conlleva a situarse en una posición de plena confianza hacia su agresor. La duración de esta etapa denota una brevedad menor que la primera fase pero superior a la segunda, por lo que intentar ofrecer ayuda en este momento no brindará ningún resultado positivo, la mujer vuelve a estar profundamente enamorada y supeditada a la voluntad de su agresor. A medida que se va repitiendo el 
ciclo esta tercera fase tiende a minimizarse hasta que acaba por desaparecer, momento en que la Luna de miel llega a su fin.

23. En resumen, en todo el ciclo de violencia de género se manifiesta:

- La sensación de que no hay salida.

- La repetición de estos ciclos es lo que suele conducir a un aumento de la violencia, lo que se traduce en un mayor peligro para la mujer, la cual empieza a pensar que no hay alternativa ni salida posible, sumergiéndose así en la más profunda rendición. Lo cierto es que, en ocasiones, acontecimientos impactantes o traumáticos dejan anclado a quien los padece en el día o época en que acontecieron, activándose así un estado de shock que puede paralizar toda la vida en un segundo.

- Denuncias que se acaban retirando.

El dominio machista, la violencia (verbal, moral, física), los intentos de separación y el feminicidio son estadios de un mismo y doloroso proceso.

Lamentablemente, este ciclo genera además una violencia indirecta, posible generadora de otras víctimas u otros victimarios.

En la mayoría de los casos, la violencia se ejerce sobre el cónyuge al que se intenta destruir. Sin embargo, también afecta a los niños. Éstos son víctimas porque están ahí y porque se niegan a distanciarse del progenitor agredido. Reciben una agresión en tanto que hijos de la víctima. Como testigos de un conflicto que no les concierne, reciben toda la maldad que éste conlleva. Por otra parte, el progenitor herido, como no consigue expresarse ante su agresor, vuelca también sobre sus hijos toda la agresividad que no ha podido exteriorizar en su momento. Frente al vituperio permanente de uno de los progenitores por parte del otro, los niños no tienen otra salida que la de aislarse, con lo que pierden cualquier posibilidad de individuación o de pensamiento propio.

En lo sucesivo, si no encuentran una solución en sí mismos, los niños llevarán consigo una parte de sufrimiento que reproducirán en otros lugares. Se trata de un desplazamiento del odio y de la destrucción. El agresor no puede contener su morbosidad y su odio pasa del excónyuge detestado a los niños, que se convierten en el objetivo que hay que destruir. (Hirigoyen 1999: 26)

\section{Ausencia de decisiones políticas comprometidas}

24. Los hechos de feminicidios son complejos, psicológica, cultural, social y políticamente, y son deficientes las formas de remediarlos. Ciudad Juárez, en Méjico, suele reunir estas deficiencias.

El 2 de junio de 2006 moría, de infarto, Abdel Latif Sharif, El Egipcio, procesado por el presunto asesinato de 15 mujeres y condenado a 20 años de prisión, por la muerte de Elisabeth Castro, la única que pudo ser probada. Condenado en principio a 30 años, se le redujo la condena a 20 en 2003. Nunca se reconoció 
culpable. Hasta hoy es el único condenado por feminicidio en Ciudad Juárez. ¿Cómo puede explicarse que, sean 300, 400 o 500 las mujeres asesinadas sin contabilizar desapariciones no se hayan realizado muchas más detenciones ni se hayan alcanzado sentencias condenatorias? Si complicada es la política, no menos lo es la justicia. (Checa Godoy 2008: 201, 194)

La vecina El Paso, ciudad norteamericana que figura entre las diez urbes más pobres de los EE. UU., no es ningún modelo de desarrollo armónico, pero aun así ofrece un gran contraste con Ciudad Juárez. Tiene fama de ciudad segura, no pasan de una docena los asesinatos anuales, lo que, en términos norteamericanos, es una delincuencia baja para una ciudad de 750.000 habitantes.

25. Existe un feminicidio que no se da en el ámbito de la intimidad de hogar, sino en situaciones más crueles e institucionalizadas.

Las estadísticas reflejan que el $50 \%$ de los feminicidios se dan en Latinoamérica. Como dijimos, de los 25 países más violentos en el mundo, 14 se encuentran en América Latina. Argentina tiene una media de un asesinato de mujer cada 30 horas con 271 asesinatos anuales (cfr. "Hubo un femicidio..." 2017; "Las estadísticas reflejan..." 2016).

Las víctimas son mujeres de escasos recursos, estudiantes, obreras, empleadas de maquiladoras; muchas son migrantes de otros estados que van a Ciudad Juárez "buscando una vida mejor”. En su mayoría son jóvenes, bien parecidas, de tez morena, de pelo y ojos oscuros y de escasos recursos económicos. Muchas son madres solteras o ayudan a la manutención del hogar. Las víctimas suelen ser secuestradas, torturadas durante varios días, golpeadas, violadas tumultuariamente, mutiladas y finalmente asesinadas, ya sean estranguladas, apuñaladas, quemadas o desangradas a causa del alambre de púas con las que se las inmoviliza. Muchos de los cadáveres muestran los pezones arrancados por dientes humanos, la piel con huellas de quemaduras de cigarrillos, la carne mordisqueada; evidencias de violencia sexual extrema y señales de prolongados tormentos.

A este fenómeno, digno de una película de terror, se le ha denominado feminicidio: el asesinato brutal y sistemático de mujeres, en el que están involucrados, por un lado, el crimen organizado y, por el otro, las autoridades del Gobierno. Cabe destacar, que no estamos hablando de violencia doméstica, que también la hay; en este caso particular se trata de una serie de asesinatos perfectamente planeados, organizados y sistematizados que han alarmado y llamado la atención de investigadores del $\mathrm{FBI}$, de periodistas, de defensores de derechos humanos y de organizaciones como Amnistía Internacional y Human Rights Watch, entre otras (Robles 2010: 96).

26. Las hipótesis que se manejan con respecto a quiénes son los probables asesinos son muy variadas, pero entre otras, se incluyen: la realización de películas snuff (grabaciones de asesinatos reales con el fin de registrar estas atrocidades y posteriormente distribuirlas comercialmente como macabro "entretenimiento"). 
Otra hipótesis es la de que llevar el pezón de una mujer, violarla o asesinarla pueden ser consideradas como pruebas de "valor" o "virilidad" para los nuevos integrantes de pandillas o de bandas de narcotraficantes que abundan en el país.

También se habla de ritos satánicos, y de fiestas - en realidad, orgías - de empresarios o personas vinculada a los gobiernos local y federal donde, como parte de la "diversión", se viola a jovencitas $y$, al final, se las sacrifica.

Sin embargo, y aunque no se sepa quiénes son los asesinos intelectuales y materiales de estos crímenes ni cuál sea su móvil, lo que sí se sabe es que la policía, las autoridades y los gobiernos estatal y federal no hacen nada para evitar, investigar y erradicar esta violencia de género. La impunidad en torno a estos asesinatos es absoluta (Robles 2010: 99).

\section{Reorganizar la convivencia social}

27. «El único caso en que puede argumentarse que el feminicidio vaya en aumento es como resultado del crimen organizado transnacional en la trata de personas... en Centroamérica y El Caribe», señaló en In Sight Crime el Representante de la Oficina de las Naciones Unidas para Droga y el Delito (ONUDD), Oficina Regional para Centroamérica y El Caribe, Amado Philip de Andrés (cfr. Yaboub 2016).

Las víctimas de estas redes que llegan a la región y salen de ella - la mayoría de las cuales tienen entre 18 y 28 años de edad - cobran cada vez más números mayores junto con víctimas mortales. El índice de feminicidios en casos de trata de personas es muy alto para las víctimas. En especial en los casos de explotación sexual, que podría representar el 91 o 92 por ciento de los casos.

Las mujeres víctimas de toda la región, así como las de otros lugares, como Europa oriental, son atraídas mediante engaños a la prostitución, donde son torturadas, violadas y muchas veces asesinadas.

28. Las interacciones con extraños ya no son una situación tranquila. El miedo no es sólo una adaptación a lo impredecible dentro de las interacciones sociales y los actos violentos; por el contrario, éste se vuelve un estado de confusión, el cual llega a ser permanente en algunos contextos.

Dado que la violencia feminicida es derivada de construcciones y condiciones sociales, culturales, políticas, entre otras, es necesario transformar la cultura de discriminación en los países, para evitar y eliminar las causas del feminicidio y erradicar la impunidad en los casos presentados, haciendo valer los derechos humanos y reconocer el cambio de paradigma, en los ámbitos político, social y cultural, donde la mujer se construye como un sujeto, capaz de crear, innovar y poner los estándares que se necesite para el pleno desarrollo de su vida.

La cuestión del feminicidio se va incrementando; por ello deben crearse no sólo instituciones protectoras de la mujer, sino condiciones de igualdad, que promuevan un 
mayor progreso como sociedad civil. Se requiere eliminar el temor a la independencia, por parte de la mujer, y erradicar costumbres proteccionistas de antaño y de control del hombre hacia la mujer, forjando un nuevo pacto social entre fuerzas, supuestamente antagónicas entre hombres y mujeres.

Un video breve de una mujer saudita vistiendo, en 2017, una minifalda por las calles de Ushayqir - cuna de la ideología conservadora saudita, conocida como wahabismo - encendió las alarmas de un Estado que castiga a las mujeres por, entre otras cosas, desafiar el statu quo y vestir así. Tras la viralización del video, la mujer fue perseguida y detenida durante varias horas por parte de las autoridades (Echenique 2017). El miedo de la mujer a la violencia del hombre es el espejo del miedo del hombre y de su machismo a la mujer sin miedo. La debilidad de los hombres para dominar sus deseos machistas que sobrevive aún en ciertos países, y en los feminicidas, requerirá una toma de conciencia por parte de los hombres, para que también ellos logren su autonomía, y todos los humanos podamos vivir más libres de nuestras propias tendencias atávicas, viviendo sin agresiones, sin provocar y sin sentirse provocados, con libertad y dejando vivir a los demás democráticamente (cfr. Gómez Ocampo 2014: 179-187). Somos animales de costumbres y llevando esto al extremo: ¿acaso no viven familias enteras en campos nudistas? ¿El problema está en los cuerpos o en las mentes? ¿Debemos cubrir los cuerpos o abrir las mentes?

\section{Concluyendo}

29. La estructura sociocultural androcéntrica asigna diferentes roles a hombres y mujeres, y sitúa éstas en una posición de subordinación a aquellos. La asignación de roles del hombre y la mujer en la pareja es una construcción que valida modos de pensar, sentir y comportarse de ambos géneros; más que tener una base natural e invariable, se deben a construcciones sociales y familiares asignadas de manera diferenciada a mujeres y hombres.

Se da un sistema generalizado de creencias que favorecen la violencia feminicida y que puede resumirse de esta manera: a) las mujeres son inferiores a los hombres, b) el hombre es el jefe del hogar, c) el hombre tiene derechos de propiedad sobre la mujer $y$ los hijos, d) la privacidad del hogar debe ser defendida de las regulaciones externas.

30. Actualmente, cuando muchas mujeres son independientes política, económica y socialmente, la independencia masculina se desmorona porque no ha encontrado todavía otro referente en el que sustentarse. Sólo le queda al hombre, cada vez menos, la dependencia emocional de bastantes mujeres, por razones mal entendidas de afectividad.

En una sociedad que pretende ser humana se requiere trabajar sobre las formas de pensar las relaciones humanas y sobre las formas de hablar: el discurso del odio pretende degradar, intimidar, promover prejuicios o incitar a la violencia contra individuos por 
motivos de su pertenencia a una raza, género, edad, colectivo étnico, nacionalidad, religión, orientación sexual, identidad de género, discapacidad, lengua, opiniones políticas o morales, estatus socioeconómico, ocupación o apariencia (como el peso, el color de pelo), capacidad mental y cualquier otro elemento de consideración.

31. Frecuentemente se estima que no hay "malos pensamientos", pero son estos los que llevan luego a acciones inaceptables. Las formas de pensar erróneas llevan luego a las formas de hablar y de actuar erróneas. Los seres humanos, si no son atacados, no suelen ser instintivamente agresivos. Si lo son, ha existido entonces un período previo de formas de pensar y de hablar agresivas y una cultura con ejemplos machistas (cfr. Peza Casares 2009: 29-35; Campbell et al. 2003: 14-19).

La cultura machista según la cual el hombre es superior a la mujer es más que milenaria y tiene orígenes documentales incluso en la Biblia.

En la Edad Media, se sigue con la misma concepción, aun sostenida por los monjes intelectuales de la época, incluido Tomás de Aquino, doctor de la Iglesia, que afirma en la Suma Teológica (Parte la, q.92, a.1):

En lo que se refiere a la naturaleza del individuo, la mujer es defectuosa y mal nacida, porque el poder activo de la semilla masculina tiende a la producción de un perfecto parecido en el sexo masculino, mientras que la producción de una mujer proviene de una falta del poder activo...

Considerada en relación con la naturaleza particular, la mujer es algo imperfecto y ocasional. Porque la potencia activa que reside en el semen del varón tiende a producir algo semejante a sí mismo en el género masculino. Que nazca mujer se debe a la debilidad de la potencia activa, o bien a la mala disposición de la materia, o también a algún cambio producido por un agente extrínseco, por ejemplo los vientos australes, que son húmedos, como se dice en el libro De Generatione Animalium. Pero si consideramos a la mujer en relación con toda la naturaleza, no es algo ocasional, sino algo establecido por la naturaleza para la generación.

En el texto Malleus Maleficarum utilizado por los monjes dominicos inquisidores, se da la siguiente tragicómica explicación de la debilidad de la mujer:

Pero la razón natural es que es más carnal que el hombre, como resulta claro de sus muchas abominaciones carnales. $Y$ debe señalarse que hubo un defecto en la formación de la primera mujer, ya que fue formada de una costilla curva, es decir, la costilla del pecho, que se encuentra encorvada, por decirlo así, en dirección contraria a la de un hombre. $\mathrm{Y}$ como debido a este defecto es un animal imperfecto, siempre engaña. iLa mujer es un mal necesario, una tentación natural, una calamidad deseable, un peligro doméstico, un deleitable detrimento, un mal de la naturaleza pintado con alegres colores! (Krämer, Sprenger: 49). 
Por ello, la extinción del feminicidio será posible si se genera una cultura que supere la concepción machista de la relación hombre-mujer y con una decidida voluntad política y judicial que ayude a cambiar esta concepción.

Resulta llamativo que habiéndose detectado un factor importante del feminicidio, como el de la amenaza de ruptura por parte de la mujer para con un hombre que la percibe como irremediable para su concepción de dominio, no existan sin embargo instrumentos específicos de protección o autoprotección. Se advierte que la motivación de la amenaza penal es prácticamente nula y requiere de otros factores inhibidores de la violencia extrema absoluta.

32. Afortunadamente los organismos internacionales están tomando conciencia de la gravedad de los hechos de feminicidios (cfr. "Femicidio en América Latina").

La Organización de las Naciones Unidas (ONU) alertó en abril de 2016 que 14 de los 25 países del mundo con las tasas más altas de feminicidio se encuentran en Latinoamérica.

Este 25 de noviembre se celebra el Día Internacional de la Eliminación de la Violencia contra la Mujer, la fecha es propicia para hacer una llamada al cese de los femenicidios y crímenes de género.

Centenares de mujeres son asesinadas en América Latina y el Caribe por una sola razón: su género. Los feminicidios han crecido en la región en los últimos años y lo más grave es que el 98 por ciento de los casos permanecen impunes.

La alerta por la limitación en la aplicación de la justicia en estos casos la encendió la Organización de las Naciones Unidas (ONU) cuando publicó en abril de este año (2017) el informe "Prevenir los Conflictos, Transformar la Justicia, Garantizar la Paz".

Como dijimos, las tasas más altas las tienen 25 países del mundo, 14 de ellos de la región de América del sur y del centro. Guatemala, El Salvador y Honduras figuran con unos de los índices más altos del planeta y en Argentina (un caso de feminicidio cada 30 hs., en 2017) y México también se reportan cifras alarmantes: las cifras que plantea el INEGI (2016) son de siete mujeres asesinadas por día (Capulín Arellano 2017: 272).

33. Se ha naturalizado la violencia: lo que es cultural se ha hecho natural. Se requiere ahora invertir el proceso: hacer ver que lo que se toma como natural (la supremacía y dominio del macho) es cultural y todo lo que han hecho los humanos lo pueden deshacer. Este proceso de desnaturalización de lo falsamente naturalizado requerirá tiempo y una decisión conjunta de las fuerzas políticas (ejecutivas, legales y judiciales), individuales, sociales y culturales. Lo importante ahora es tomar conciencia e iniciar este proceso.

El contexto sociocultural actual permite que la perversión se desarrolle porque la tolera. Nuestra época rechaza el establecimiento de normas. Nombrar la manipulación perversa supone establecer un límite, lo que se identifica con una intención de censura. Hemos perdido los límites morales o religiosos que constituían un código de civismo y que podían hacernos decir: “iEso no se hace!». Sólo nos volvemos a encontrar con nuestra 
capacidad de indignarnos cuando los hechos aparecen en la escena pública, presentados y amplificados por los medios de comunicación. El poder no establece un marco de acción y elude sus responsabilidades al respecto de las gentes a las que supuestamente dirige o ayuda. Los mismos psiquiatras se muestran dubitativos a la hora de nombrar la perversión, y sólo lo hacen para expresar su incapacidad de intervenir, o bien para mostrar su curiosidad ante la habilidad del manipulador. Algunos de ellos discuten la misma definición de perversión moral y prefieren hablar eufemísticamente de psicopatía (Hirigoyen 1999: 7).

34. En Francia existe, desde 1994, un curso de formación en victimología que conduce a un diploma universitario. El curso se dirige a los médicos de urgencia, a los psiquiatras y terapeutas, a los juristas y a toda persona que tenga la responsabilidad profesional de ayudar a las víctimas. Una persona que ha padecido una agresión psíquica como el acoso moral es realmente una víctima, puesto que su psiquismo se ha visto alterado de un modo más o menos duradero. Pero en el caso de feminicidio, la víctima ya no tiene ninguna posibilidad, pues el final de vida es el final de las posibilidades. Urge entonces desarmar física, social y moralmente a los victimarios.

Los pequeños actos perversos son tan cotidianos que parecen normales. Empiezan con una sencilla falta de respeto, con una mentira o con manipulación. Pero sólo los encontramos insoportables si nos afectan directamente. Luego, si el grupo social en el que aparecen no reacciona, estos actos se transforman progresivamente en verdaderas conductas perversas que tienen graves consecuencias para la salud psicológica de las víctimas. Al no tener la seguridad de que serán comprendidas, las víctimas callan y sufren y mueren.

35. Mas está surgiendo una firme reacción: "Mujeres y niñas, familias completas asisten a exigir seguridad para sus vidas, justicia para las ya perdidas y aparición con vida de las desaparecidas. Una pancarta sobresale por ser portada por una niña; se lee "quiero crecer y decir sin miedo y con mucho orgullo, soy mujer" (Capulín Arellano 2017: 267).

El hecho del feminicidio parece poner a la luz la complejidad del problema humano, tanto psicológico como social; por esto se puede hacer la interpretación hipotética de que no hay manera de liberar al hombre mientras la mujer no se libere del hombre; y que mientras los hombres continúen oprimiendo a las mujeres, no hay posibilidad alguna de liberación de la humanidad en su conjunto. Se trata de comprender la complejidad de la pluralidad de las formas de vida y de convivencia, y luego de no imponer una de ellas a las otras, de modo que la seguridad social ni impida las diversas formas individuales de vida y de convivencia.

La identidad de la mujer moderna tiene en su raíz el mismo factor dominante de las identidades modernas masculinas: la aspiración a la realización individual y la consecuente exigencia de libre disposición de la propia existencia. Este factor es común a mujeres y hombres; pero ahora les toca el tiempo a las mujeres y los hombres tienen miedo a tal libertad. Han atendido a un modelo de humanidad en la que primen libertad, autonomía, racionalidad (lo que es, en cierto modo, un modelo de humanidad 
asexuada). En este contexto, los hombres estiman que pueden estar pasando a un segundo plano, en el que las mujeres pueden prescindir de ellos y a ellos les urge poseerlas.

Las sociedades ultramodernas activan algo así como una coerción a la libertad. Todos se ven urgidos a elegir y decidir. Los hombres ya lo hicieron, pero ahora, sin distinción de sexo, todos quieren elegir como si esto garantizara alguna forma de felicidad, más aún, como si fuera el requisito para ella. Más a la elección se sigue la responsabilidad y frecuentemente, ante el fracaso, la soledad $y$, ante la incapacidad del hombre para resistir a la frustración, el feminicidio: será mi posesión o la de nadie.

\section{BIBLIOGRAFÍA}

Alvazzi del Frate, Anna. When the Victim Is a Woman. Geneva Declaration Secretariat, 2011. 113-144. Web.

Ayala, Saray et al. "Diferencias, discriminación, cerebro y sexo: controversias científicas de lo social y lo biológico". Encrucijadas. Revista Crítica de Ciencias Sociales, 8 (2014): 3-9. Web.

Beck, Ulrich. La sociedad del riesgo: Hacia una nueva Modernidad. Buenos Aires: Paidós, 2008. Impreso.

Boddice, Rob. "The Manly Mind? Revisiting the Victorian "Sex in Brain" Debate". Gender \& History, 23.2 (2011): 321-340. Web.

Bourdieu, Pierre. La dominación masculina. Barcelona: Anagrama, 2000. Impreso.

Bower, Lorena y Oscar Muñoz Zaccaro. "Yerros del amor. De estragos y feminicidios". $V$ Congreso Internacional de Investigación y Práctica Profesional en Psicología XX Jornadas de Investigación Noveno Encuentro de Investigadores en Psicología del MERCOSUR. Buenos Aires: Facultad de Psicología - Universidad de Buenos Aires, 2013. 93-95. Acta academica. Web.

Brizendine, Louann. The Female Brain. New York: Morgan Road Books, 2006. Print.

Butler, Judith. Cuerpos que importan. Sobre los límites materiales y discursivos del "sexo". Buenos Aires: Paidós, 2002. Impreso.

Caballero González, Manuela. «Mujer y tecnología: las primeras murcianas en patentar un invento". Andelma, 23 (2014): 34-43. Web.

Campbell, J. C. et al. "Assessing risk factors for intimate partner homicide". National Institute of Justice Journal, 250 (2003): 14-19. Web.

Capulín Arellano, Lizeth. “Breves apuntes sobre la niñez". Teoría y Crítica de la Psicología, 9 (2017): 265-273. Web.

Checa Godoy, Antonio. "Ciudad Juárez: feminicidios, sociedad y medios". Visiones de América: comunicación, mujeres e interculturalidad. Oleiros, La Coruña: Netbiblo, 2008. 193-211. Impreso. 
Collignon Goribar, María Martha y Paola Lazo Corvera. "Derechos humanos/sexuales, género y biopolítica: Reflexiones sobre la configuración subjetiva del derecho a la libre elección de identidad de género". La ventana. Revista de estudios de género, 45 (Enero - Junio de 2017): 50-87. Web.

Córdoba, María y Amílcar Pérez. "Roles para el hombre y la mujer, en casos vinculados con la violencia de pareja en Santo Domingo, 2011". Ciencia y sociedad, 37.1 (Enero - Marzo 2012): 5-42. Web.

Daros, William Roberto. “El problema de la libertad en la teoría psicoanalítica freudiana. Observaciones rosminianas". Rivista Rosminiana, III (1979): 249-272. Impreso.

—. "La mujer posmoderna y el machismo". Franciscanum, 162.56 (2014): 107-129. Web.

Echenique, Martín. "Un reino entre la tradición y el cambio. La minifalda que desató un "terremoto" en Arabia Saudita". Clarín, 21/07/2017. Web.

"Femicidio en América Latina”. Telesur. Web.

Fernández Teruelo, Javier Gustavo. “Feminicidios de género: Evolución real del fenómeno, el suicidio del agresor y la incidencia del tratamiento mediático". Revista Española de Investigación Criminológica, 9 (2011): 1-27. Web.

Figueroba, Alex. "Feminicidio (asesinatos a mujeres): definición, tipos y causas". Psicología y Mente. Web.

Fine, Cordelia. Delusions of Gender: How Our Minds, Society, and Neurosexism Create Difference. New York: W. W. Norton, 2010. Print.

Gago, Mauro. "La concepción freudiana de Eros y Tánatos y la disciplina conocida como Tanatología". Grecia aplicada, 09/11/2012. Web.

García Soormally, Mina. Magia, hechicería y brujería. Madrid: Renacimiento, 2011. Impreso.

"Gen masculino podría extinguirse, afirma científica australiana". Spanish.People.com.cn. 07/04/2013. Web.

Gil Soldevilla, Samuel. "La mujer en el Nuevo Testamento". Aula7activa-AEGUAE, 2009. Academia.edu. Web.

Giberti, Eva. “iTe voy a quemar viva!» Santiago de Chile: Red Chilena Contra la Violencia Domestica, 2010. Web.

Gómez Ocampo, Néstor Andrés. “Revisión de literatura: acontecer del género como experiencia de emancipación de la mujer y subyugación de las identidades sexuales y de género". Episteme, 6.2 (2014): 179-187. Web.

Hansson, Sven Ove. "Science and Pseudo-Science". Edward N. Zalta (ed.). The Stanford Encyclopedia of Philosophy, (Spring 2015 Edition). Web.

Hirigoyen, Marie-France. El acoso moral. El maltrato psicológico en la vida cotidiana. Barcelona: Paidós, 1999. eBook. Lectulandia. Web.

"Hubo un femicidio cada 25 horas entre enero y abril de 2017". Todo noticias, 29/04/2017. Web.

INEGI (2016). Estadísticas a propósito del día internacional de la eliminación de la violencia contra la mujer (25 de noviembre). Datos nacionales. Web. 25 Nov. 
2016.

Informe de la Cuarta Conferencia Mundial sobre la mujer, Beijing, 4 a 15 de septiembre de 1995. New York: Naciones Unidas, 1996. Web.

Krämer, H y Sprenger, J. Malleus Maleficarum. Segunda parte. 1487. Digilib.hab.de. Web.

Lamas, Marta. "Usos, dificultades y posibilidades de la categoría género". La Ventana. Revista de Estudios de Género, 1 (1995): 9-53. Web.

"Las estadísticas reflejan que el $50 \%$ de los feminicidios se dan en Latinoamérica". El diario 24, 26/11/2016. Web.

Maffia, Diana. "Cuerpos, fronteras, muros y patrullas". Revista Científica de UCES XIII, 2 (2009): 217-226. Web.

-. "Epistemología feminista: la subversión semiótica de las mujeres en la ciencia". Revista Feminismos, 2.3 (2014): 108-109. Web.

Martínez Martín, Miquel. "La Educación moral: una necesidad en las sociedades plurales y democráticas". Revista Iberoamericana de Educación, 7 Educación y Democracia 1 (1995). Web.

Marx, Karl. Elementos fundamentales para la crítica de la economía política (Grundrisse) 1857-1858 I. 1858. México: Siglo XXI, 2009. Impreso.

Marx, Karl y Friedrich Engels. La ideología alemana. 1846. Madrid: Akal, 2014. Impreso.

Muñoz Mainato, Manuel Enrique. "Antropología del cuerpo y el dolor". Universitas, 14.24 (2016): 41-62. Web.

Naciones Unidas. The world's women 2015. Trends and statistics. New York: Naciones Unidas, 2015. Web.

Opitz, Claudia. “Vida cotidiana de las mujeres en la Baja Edad Media (1250-1500)". Georges Duby y Michelle Perrot (Dirs.). Historia de las mujeres en Occidente. Tomo 2, La Edad Media. Madrid: Taurus, 1992: 321-390. Impreso.

Organización Mundial de la Salud. Understanding and addressing violence against women. Ginebra: Organización Mundial de la Salud, 2012. Impreso.

Pavón-Cuéllar, David. "¿Por qué la violencia de género no puede explicarse por la de clase? Marxismo y psicoanálisis ante el fundamento sexual-familiar de la opresión política-económica”. Teoría y Crítica de la Psicología, 9 (2017): 244-253. Web.

Peza Casares, María del Carmen de la. "Discursos de odio y feminicidios en México". Anclajes, 66 (2009): 29-35. Web.

Puig, Raquel. "Las causas y los efectos de la violencia de género". Psicología y Mente. Web.

Radford, Jill and Diana E. H. Russell. Femicide: The politics of woman killing. New York: Twayne, 1992. Print.

Reverter-Bañón, Sonia. “Reflexión crítica frente al neurosexismo". Pensamiento, 72.273 (2016): 959-979. Web.

Robles, Humberto. "Ciudad Juárez: donde ser mujer es vivir en peligro de muerte". Papeles de relaciones ecosociales y cambio global, 109 (2010): 95-104. Web. 
Rodríguez, Irene. "Cromosoma sexual masculino está cerca de su desaparición". 06/09/2009. Costa Rica Inclusiva. Web.

Rodríguez Kauth, Ángel et al. "El machismo en el imaginario social". Revista Latinoamericana de Psicología, 2.25 (1993): 275-284. Web.

Rosales, María Belén. “Configuraciones semánticas del cuerpo femenino: un análisis crítico del tratamiento mediático de los feminicidios". Políticas feministas, 2 (Junio 2013): 32-42. Web.

Rose, Nikolas. "Reading the Human Brain: How the Mind Became Legible". Body \& Society, 22.2 (2016): 140-177. Web.

Rose, Nikolas and Joelle M. Abi-Rached. Neuro: The New Brain Sciences and the Management of the Mind. Princeton: Princeton University Press, 2013. Print.

Roskies, Adina. “Neuroethics for the new Millenium”. Neuron, 35.1 (2002): 21-23. Web.

—. "Neuroimaging and inferencial distance". Neuroethics, 1 (2008): 19-30. Web.

Russell, Diana E. H. "Definición de feminicidio y conceptos relacionados". Feminicidio, justicia y derecho, México, Comisión Especial para Conocer y Dar Seguimiento a las Investigaciones Relacionadas con los Feminicidios en la República Mexicana y a la Procuración de Justicia Vinculada, 2005. Web.

Russell, Diana E. H. and Roberta A. Harmes. Femicide in global perspective. New York: Teachers College Press, 2001. Print.

Sagot, Montserrat. “Estrategias para enfrentar la violencia contra las mujeres: reflexiones feministas desde América Latina». Athenea Digital, 14 (2008): 215-228. Web.

Salles, Arleen. "Las diferencias sexuales y la discusión neuroética". Debate Feminista, 49 (2014): 94-115. Web.

Santa Cruz, María Isabel et al. Mujeres y Filosofía. Teoría Filosófica de Género. Vol. 1. Buenos Aires: Centro Editor de América Latina, 1994. Impreso.

Secretariado de la Campaña del Secretario General de las Naciones Unidas ÚNETE para poner fin a la violencia contra las mujeres La regulación del delito de en América Latina y el Caribe. Femicidio/feminicidio. Ciudad de Panamá, Panamá, 2011.

Segato, Rita. Las estructuras elementales de la violencia. Ensayos sobre género entre la antropología, el psicoanálisis y los derechos humanos. Buenos Aires: Prometeo y Universidad Nacional de Quilmes, 2003. Impreso.

Thomasset, Claude. "La naturaleza de la mujer". Georges Duby y Michelle Perrot (Dirs.), Historia de las mujeres en Occidente. Tomo 2, La Edad Media. Madrid: Taurus, 1992. 61-92. Impreso.

Triglia, Adrián. "Psicología del sexismo: 5 ideas machistas que se dan en la actualidad. Cinco concepciones machistas que, a pesar de los avances, siguen bien presentes en Occidente". Psicología y Mente. Web.

Universidad Nacional del Nordeste, Facultad de Ciencias agrarias, Corrientes. "Reproducción asexual”. Hipertextos del área de la biología. s. a. Web.

Vergés Bosch, Núria. "Una década de feminicidios en el Estado Español". Arte y políticas de identidad, 6 (2012): 145-159. Web. 
Vidal, Catherine. "The Sexed Brain: Between Science and Ideology". Neuroethics, 5.3 (2011): 295-303. Web.

Walby, Sylvia. Theorizing Patriarchy: patriarchal and capitalist relations in employment. Oxford: Polity Press, 1997. Print.

Yaboub, Mimi. “iPor qué Latinoamérica tiene las tasas de feminicidios más elevadas del mundo?" Insight Crime, 12/02/2016. Web.

Fecha de recepción: 28 de septiembre de 2017. Fecha de aceptación: 21 de enero de 2018. 